\title{
Matlab-Based Modeling and Simulations to Study the Performance of Different MPPT Techniques Used for Photovoltaic Systems under Partially Shaded Conditions
}

\author{
Jehun Hahm, ${ }^{1}$ Jaeho Baek, ${ }^{2}$ Hyoseok Kang, ${ }^{3}$ Heejin Lee, ${ }^{4}$ and Mignon Park ${ }^{1}$ \\ ${ }^{1}$ Intelligent Control System Laboratory, Yonsei University, Shin Chon Campus, B2 Building 723, Seoul 120-749, Republic of Korea \\ ${ }^{2}$ Advanced R\&D Team, Samsung Electronics Co. Ltd., Suwon, Republic of Korea \\ ${ }^{3}$ MathWorks Korea, LLC, Gangnam-gu, Seoul, Republic of Korea \\ ${ }^{4}$ Hankyong National University, Anseong Campus, S Building 409, Kyonggi-do, Republic of Korea
}

Correspondence should be addressed to Mignon Park; mignpark@yonsei.ac.kr

Received 8 October 2014; Revised 17 December 2014; Accepted 20 December 2014

Academic Editor: Wayne A. Anderson

Copyright (C) 2015 Jehun Hahm et al. This is an open access article distributed under the Creative Commons Attribution License, which permits unrestricted use, distribution, and reproduction in any medium, provided the original work is properly cited.

\begin{abstract}
A pulse-width-modulator- (PWM-) based sliding mode controller is developed to study the effects of partial shade, temperature, and insolation on the performance of maximum power point tracking (MPPT) used in photovoltaic (PV) systems. Under partially shaded conditions and temperature, PV array characteristics become more complex, with multiple power-voltage maxima. MPPT is an automatic control technique to adjust power interfaces and deliver power for a diverse range of insolation values, temperatures, and partially shaded modules. The PV system is tested using two conventional algorithms: the Perturb and Observe (P\&O) algorithm and the Incremental Conductance (IncCond) algorithm, which are simple to implement for a PV array. The proposed method applied a model to simulate the performance of the PV system for solar energy usage, which is compared to the conventional methods under nonuniform insolation improving the PV system utilization efficiency and allowing optimization of the system performance. The PWM-based sliding mode controller successfully overcomes the issues presented by nonuniform conditions and tracks the global MPP. In this paper, the PV system consists of a solar module under shade connected to a boost converter that is controlled by three different algorithms and is generated using Matlab/Simulink.
\end{abstract}

\section{Introduction}

Photovoltaic generation (PVG) systems are widely used as energy sources in hybrid, stand-alone, and grid-connected systems. Because of natural environmental disasters and concerns over fossil fuel reserves, there is a great amount of interest in clean energy sources that cause less environmental pollution than fossil fuels. Among the various renewable energy sources, photovoltaic (PV) energy is one of the most reliable and mature alternative energies. PV energy is pollution-free, long-life, has no running cost, and is very low maintenance. However, there are some drawbacks to the PV system, such as the high installation cost and low conversion efficiency (12-15\%) of PV modules. PV cell technology is expected to perform an important function in meeting the growing demand for stand-alone systems at low voltages and also in high power installations, which are usually connected to the grid. PVG has the advantage of directly converting light energy into electrical energy through semiconductors.

Maximum power point tracking (MPPT) of a PV array is usually an essential part of the PVG system. If weather conditions, such as ideal insolation and temperature, are good, the PVG system can generate maximum power efficiently. However, nonuniform insolation occurs frequently due to shadowing from sources such as trees, electric poles, neighboring buildings, and clouds [1].

Many MPPT algorithms and techniques have been developed. The most widely used algorithms are the Perturb and Observe ( $\mathrm{P} \& \mathrm{O})$ algorithm and the Incremental Conductance (IncCond) algorithm [2, 3]. The $\mathrm{P} \& \mathrm{O}$ algorithm is well known for its simple implementation, but it deviates from and oscillates around the maximum power point (MPP), thereby 
wasting a considerable amount of the available energy. In addition, the $\mathrm{P} \& \mathrm{O}$ algorithm can become confused when insolation and temperature atmospheric conditions change rapidly [4]. The IncCond algorithm has good efficiency and accuracy. This algorithm can track the MPP of the PV module by comparing instantaneous conductance with Incremental Conductance [5]. Therefore, under rapidly changing temperature and insolation atmospheric conditions, it performs well, but its response in finding the MPP is reduced due to the relatively complex computations required by the control algorithm [5-7].

Partially shaded PV modules typically have difficulty in tracking the global maximum power point (GMPP). The operating point of the PVG system tends to converge to a local MPP. Most traditional MPPT algorithms converge to a local maximum, which is not the global maximum output point on the $P-V$ curve. This results in a considerable decrease in PVG, in addition to the efficiency of the MPPT algorithm. To resolve this problem, partially shaded PV modules can be implemented using a PWM-based sliding mode controller.

In this paper, we propose a PWM-based sliding mode controller to track the maximum power point in a nonuniform $P-V$ curve. Within this paper and taking into consideration the effects of changes in insolation and temperature on the PV system under a shaded module, three MPPT methods that build on the P\&O and IncCond algorithms and the proposed controller are implemented, evaluated, and compared in a Matlab/Simulink environment. The advantage of this implementation is that it takes advantage of electronic components and sampling frequencies, so its performance is relatively simple, as is its implementation, which can be done with microcontrollers and digital programming. We perform simulations to validate the effectiveness and robustness of the proposed controller method.

The paper is organized as follows: modelling of the PV system and the power output of a partially shaded PV array are described in Section 2; the proposed PWM-based sliding mode controller system and the two conventional algorithms are presented in Section 3; simulation results for the different MPPT algorithms with partially shaded PV modules with a focus on variations in insolation, temperature, and load are described in Section 4; and we present conclusions in Section 5 .

\section{Photovoltaic System Modeling}

A model for a PV cell was introduced previously [8]. By using the equivalent circuit of a single diode model as shown in Figure 1, the generated current can be expressed as

$$
I_{\mathrm{PV}}=N_{p}\left[I_{p h}-I_{o}\left\{e^{q\left(V_{\mathrm{PV}}+R_{s} I_{\mathrm{PV}}\right) / A k T N_{s}}-1\right\}-\frac{V_{\mathrm{PV}}+R_{s} I_{\mathrm{PV}}}{N_{s} R_{p}}\right],
$$

where $I_{\mathrm{PV}}$ and $V_{\mathrm{PV}}$ represent the $\mathrm{PV}$ array output current and voltage and $R_{s}$ and $R_{p}$ are the PV array series and shunt resistances, respectively. $I_{p h}$ is the light-generated current, $I_{o}$ is the diode reverse saturation current, $A$ is a dimensionless junction material factor, $k$ is Boltzmann's constant $(1.3805 \times$

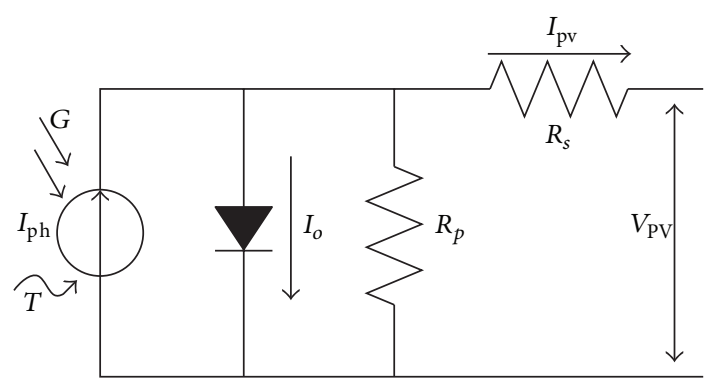

FIGURE 1: Equivalent circuit model of a PV cell.

TABLE 1: Specifications of the KC200GT solar module at $25^{\circ} \mathrm{C}$, $1000 \mathrm{~W} / \mathrm{m}^{2}$ from the datasheet.

\begin{tabular}{lc}
\hline Designation & KC200GT \\
\hline Maximum power $\left(P_{\max }\right)$ & $200.143 \mathrm{~W}$ \\
Voltage at maximum power $\left(V_{\mathrm{mp}}\right)$ & $26.3 \mathrm{~V}$ \\
Current at maximum power $\left(I_{\mathrm{mp}}\right)$ & $7.61 \mathrm{~A}$ \\
Open circuit voltage $\left(V_{\mathrm{oc}}\right)$ & $32.9 \mathrm{~V}$ \\
Short circuit current $\left(I_{\mathrm{sc}}\right)$ & $8.21 \mathrm{~A}$ \\
Temperature coefficient of $V_{\mathrm{oc}}\left(K_{V}\right)$ & $-123 \mathrm{mV} /{ }^{\circ} \mathrm{C}$ \\
Temperature coefficient of $I_{\mathrm{sc}}\left(K_{I}\right)$ & $3.18 \mathrm{~mA} /{ }^{\circ} \mathrm{C}$ \\
Number of cells $\left(N_{s}\right)$ & 54 \\
\hline
\end{tabular}

$\left.10^{-23} \mathrm{~J} / \mathrm{K}\right), T$ is the temperature in Kelvin, $q$ is the electric charge $\left(1.6021 \times 10^{-19} \mathrm{C}\right)$, and $N_{p}$ and $N_{s}$ are the numbers of cells connected in parallel and series, respectively.

The PV module type is KC200GT, and its specifications are reported in Table 1.

The characteristic $P-V$ curves of the PV array system shown in Figure 2 depend on the insolation and temperature of the PV system. However, insolation is not equally distributed to partially shade the PV module. To test the approach, three PV arrays are connected in series as shown in Figure 3. The following three cases of partially shaded PV modules are considered.

Case (a): one module is shaded with unequal insolation (i.e., PV module 3).

Case (b): two modules are partially shaded with unequal insolation (i.e., PV modules 2 and 3).

Case (c): three modules are partially shaded with different insolation (i.e., PV modules 1, 2, and 3).

The simulation results for the three cases suggest that a partially shaded module causes a reduction in PV output power. PV output power characteristics for all cases are depicted in Figure 4.

\section{Presentation of the MPPT Algorithms}

In this section, we compare the performance of the proposed algorithm with two published algorithms $[5,9]$. The proposed algorithm is based on the PWM-based sliding mode controller algorithm with step-size variations; when partial 


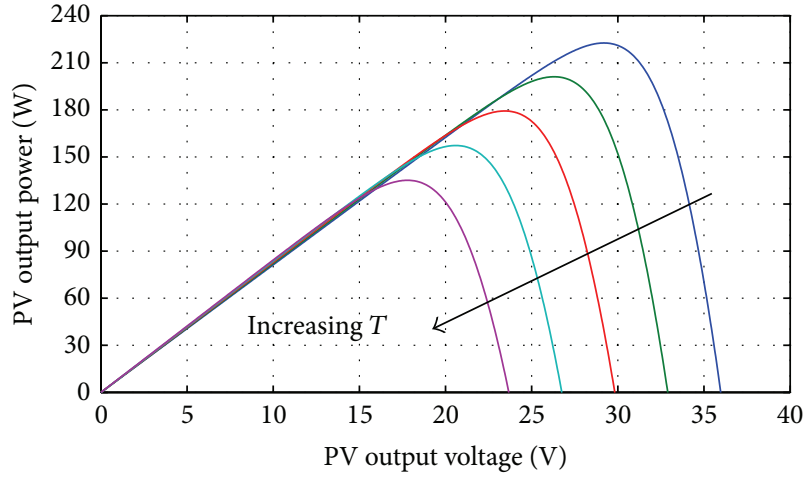

(a)

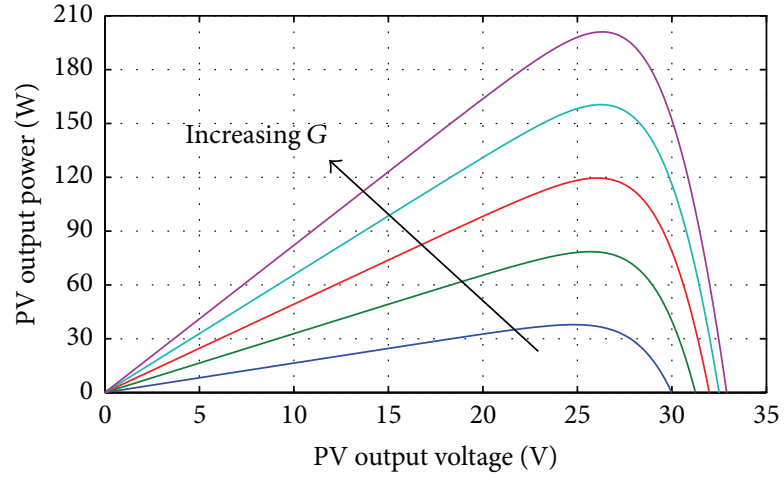

(b)

FIgURE 2: Influence of (a) temperature (T) and (b) solar insolation $(G)$ on the $P-V$ characteristic.

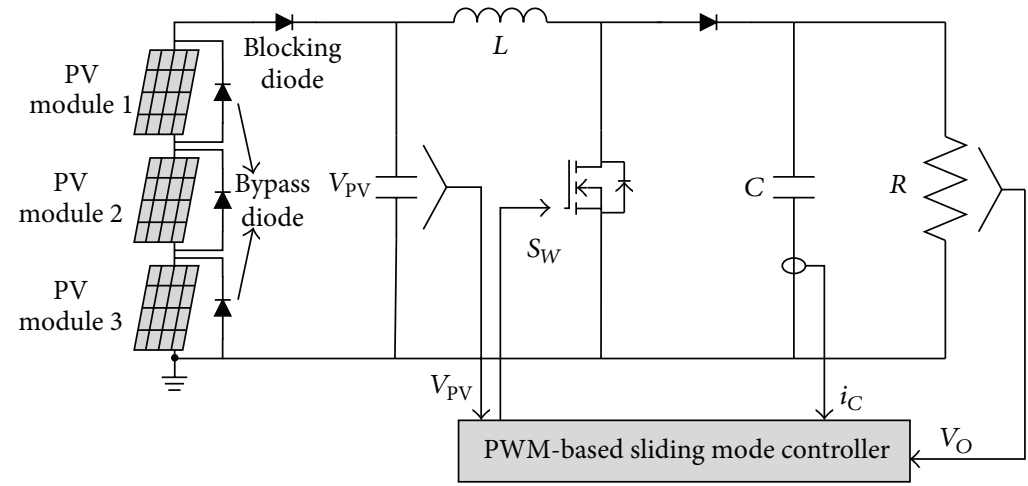

FIGURE 3: Simplified schematic of the overall PV system configuration implementing a PWM-based sliding mode controller.

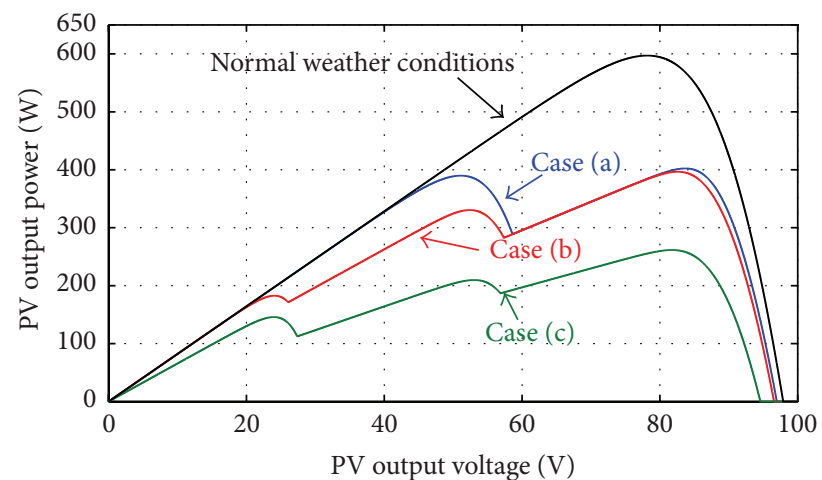

FIGURE 4: PV output power characteristics under different partial shade conditions (three cases).

shade conditions are detected, the MPPT method changes the voltage reference according to a linear function [10-12].

3.1. Perturb and Observe MPPT Algorithm. PV output power is basically a response to environmental factors such as changes in insolation and temperature. Thus, for effective PV power generation, it is desirable to have a MPPT algorithm. The P\&O algorithm is widely used because it has a simple control structure and only measurements of parameters $I_{\mathrm{PV}}$ and $V_{\mathrm{PV}}$ are required for power tracking. In the experiment, $\mathrm{PV}$ voltage, current, and power for the $k$ th are measured each time, where the time $k-1$ corresponds to the previous time $t-1$, while $k$ suggests the real cycle calculated values [13]. The actual power value $P_{\mathrm{pV}}(k)$ and previous power value $P_{\mathrm{PV}}(k-1)$ are compared to track the actual maximum power $P_{m}(k)$. If the actual power $P_{\mathrm{PV}}(k)$ has increased, $V_{\mathrm{PV}}$ of the $\mathrm{PV}$ array voltage is adjusted in the same direction; otherwise, if $P_{\mathrm{PV}}(k)$ has decreased, it is perturbed in the opposite direction as in the previous cycle [3], as shown in Figure 5. The process is repeated periodically when the MPP is reached. The method oscillates around the optimal value. The process leads to power loss that increases with perturbation step size. The MPPT algorithm responds rapidly to sudden changes in the operating conditions. However, with a smaller perturbation step size, the losses under stable or slowly changing conditions will be lower. This method does not respond to rapid changes in insolation or temperature [14].

3.2. Incremental Conductance MPPT Algorithm. In the Incremental Conductance (IncCond) algorithm, the PV array output voltage is tracked continuously according to the MPP voltage by comparing the instantaneous conductance $\left(I_{\mathrm{PV}} / V_{\mathrm{PV}}\right)$ to the Incremental Conductance $\left(\Delta I_{\mathrm{PV}} / \Delta V_{\mathrm{PV}}\right)$ to adjust the operating point on the characteristic $I-V$ curve to the MPP corresponding voltage [5]. The ratio of the PV power 


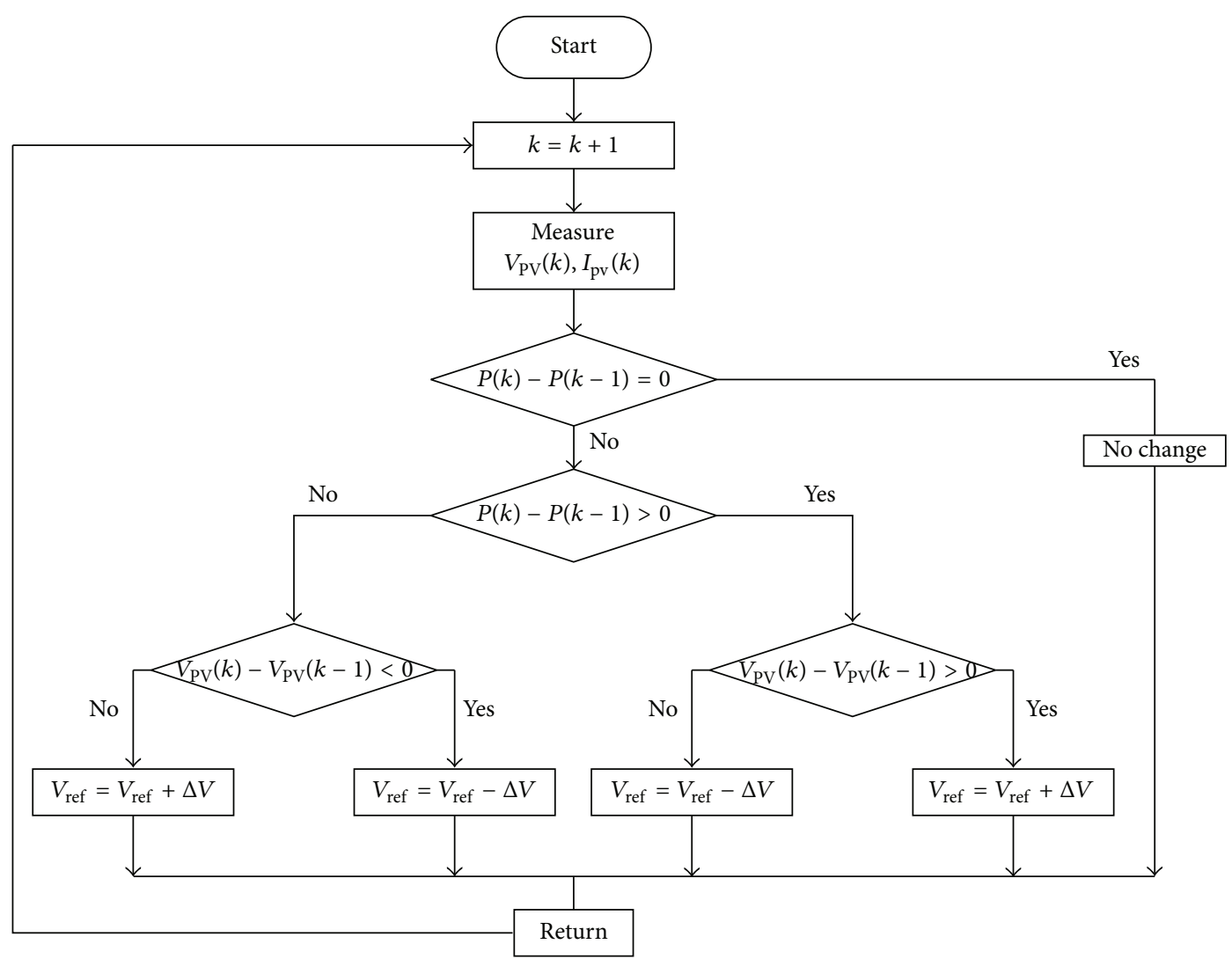

FIgURE 5: Flowchart of the Perturb and Observe algorithm.

is equal to zero at the MPP, is positive to the left of the MPP, and is negative to the right of the MPP $[7,15,16]$, as given by

$$
\begin{gathered}
\frac{d P_{\mathrm{PV}}}{d V_{\mathrm{PV}}}=\frac{d\left(V_{\mathrm{PV}} \cdot I_{\mathrm{PV}}\right)}{d V_{\mathrm{PV}}}=I_{\mathrm{PV}}+V_{\mathrm{PV}} \frac{d I_{\mathrm{PV}}}{d V_{\mathrm{PV}}} \cong I_{\mathrm{PV}}+V_{\mathrm{PV}} \frac{\Delta I_{\mathrm{PV}}}{\Delta V_{\mathrm{PV}}} \\
\Longrightarrow \begin{cases}\frac{\Delta P_{\mathrm{PV}}}{\Delta V_{\mathrm{PV}}}>0 & \text { if } \frac{I_{\mathrm{PV}}}{V_{\mathrm{PV}}}>-\frac{\Delta I_{\mathrm{PV}}}{\Delta V_{\mathrm{PV}}}, \text { left of MPP } \\
\frac{\Delta P_{\mathrm{PV}}}{\Delta V_{\mathrm{PV}}}=0 & \text { if } \frac{I_{\mathrm{PV}}}{V_{\mathrm{PV}}}=-\frac{\Delta I_{\mathrm{PV}}}{\Delta V_{\mathrm{PV}}}, \text { at MPP } \\
\frac{\Delta P_{\mathrm{PV}}}{\Delta V_{\mathrm{PV}}}<0 & \text { if } \frac{I_{\mathrm{PV}}}{V_{\mathrm{PV}}}<-\frac{\Delta I_{\mathrm{PV}}}{\Delta V_{\mathrm{PV}}}, \text { right of MPP. }\end{cases}
\end{gathered}
$$

The MPP can be tracked by comparing the instantaneous $\left(I_{\mathrm{PV}} / V_{\mathrm{PV}}\right)$ to the Incremental Conductance $\left(\Delta I_{\mathrm{PV}} / \Delta V_{\mathrm{PV}}\right)$ as shown in Figure 6. $V_{\text {ref }}$ is the reference voltage at which the $\mathrm{PV}$ array is forced to operate. At the MPP, $V_{\text {ref }}$ equals $V_{\mathrm{MPP}}$. Once the MPP is reached, the operation of the PV array is maintained at this point unless a change in $\Delta I_{\mathrm{PV}}$ is noted, indicating a change in the atmospheric conditions and the MPP. The algorithm decrements or increments $V_{\text {ref }}$ to track the new MPP [17].

\subsection{Proposed MPPT Algorithm Based on a PWM-Based} Sliding Mode Controller. Sliding mode (SM) controllers are well known for their robustness, stability, and advantages for application in nonlinear control systems. SM controllers are naturally better candidates than conventional PWM controllers due to their superb robustness and stability properties in handling variable switching frequencies [10]. The function of a switching control law is to drive the nonlinear plant state trajectory onto a previous surface and to maintain the plant state trajectory for the subsequent time. The surface is known as the switching surface, which establishes rules for appropriate switching [11]. The overall diagram of the proposed SM voltage control boost converters is presented in Figure 7. The system parameters are $C$, which is the capacitance of the output filter; $L$, which is the inductance of the input circuit; and $R_{L}$, which is the load resistance of the converters. $i_{C}$ is the capacitor current, $i_{L}$ is the inductor current, and $i_{R}$ is the load current.

For any PID SMVC converter, the control variables $x$ for the equation of the controlled system can be formed as

$$
x=\left[\begin{array}{l}
x_{1} \\
x_{2} \\
x_{3}
\end{array}\right]=\left[\begin{array}{c}
V_{\text {ref }}-\beta V_{o} \\
\frac{d\left(V_{\text {ref }}-\beta V_{o}\right)}{d t} \\
\int\left(V_{\text {ref }}-\beta v_{o}\right) d t
\end{array}\right],
$$

where $x_{1}, x_{2}$, and $x_{3}$ represent the voltage error, the voltage error dynamics (or the rate of change of the voltage error), and the integral of the voltage error, respectively. $V_{\text {ref }}, v_{i}$, and $\beta v_{o}$ are, respectively, the reference, instantaneous input, and instantaneous output voltages. The switching state of the 


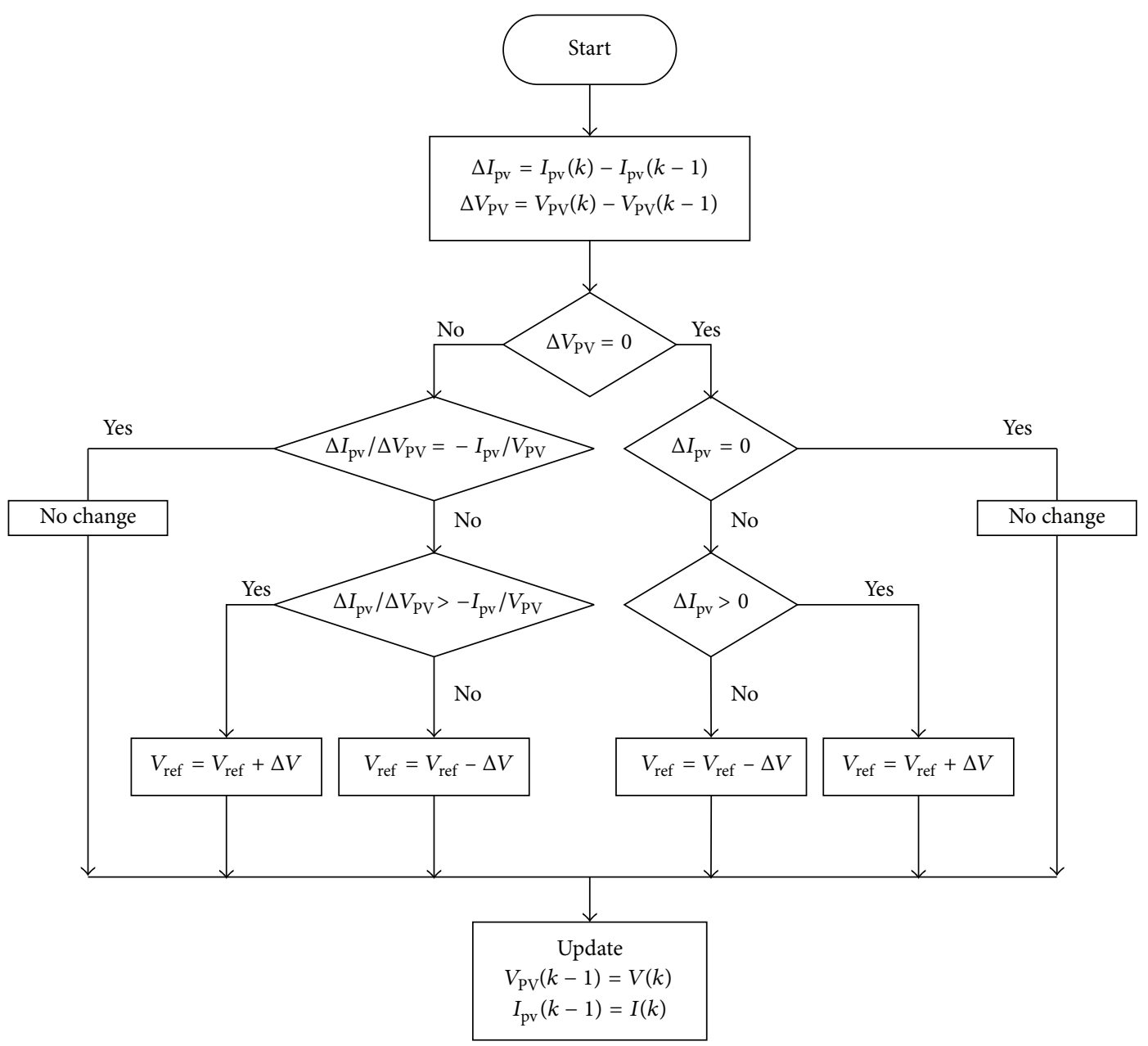

FIGURE 6: Flowchart of the Incremental Conductance algorithm.

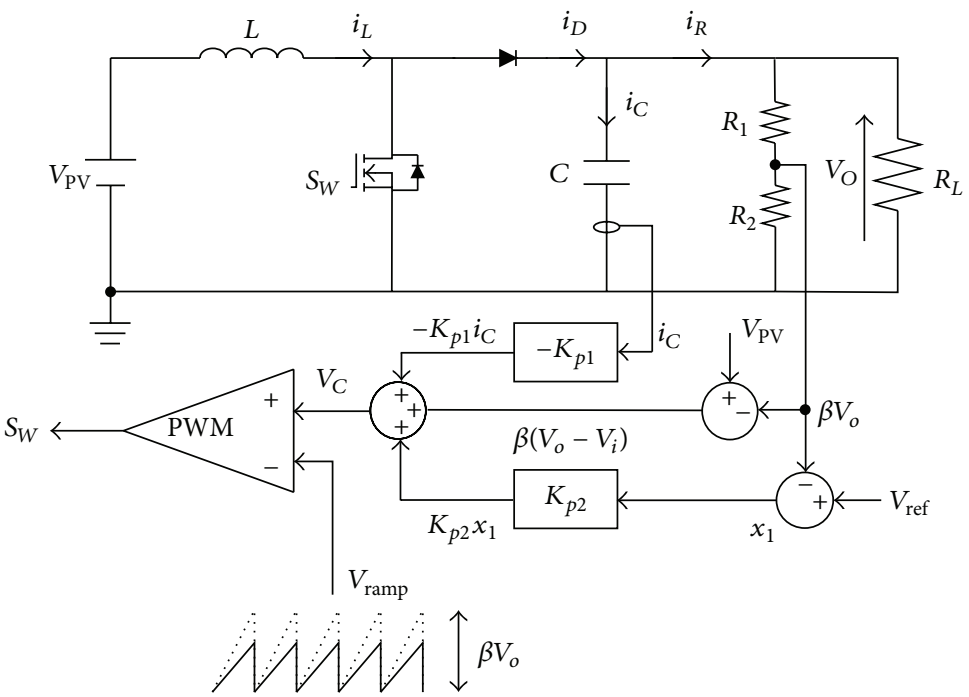

FIGURE 7: Schematic diagram of the PWM-based PID sliding mode voltage controller for a DC-DC boost converter. 
power switch $S_{W}$ is $u=0$ or 1 . The state space model of the system can then be written in the form of a state space description as follows:

$$
\begin{aligned}
& \dot{x}=A x+B \bar{u}, \\
& A=\left[\begin{array}{ccc}
0 & 1 & 0 \\
0 & -\frac{1}{r_{L} C} & 0 \\
1 & 0 & 0
\end{array}\right], \quad B=\left[\begin{array}{c}
0 \\
\frac{\beta v_{o}}{r_{L} C}-\frac{\beta v_{i}}{L C} \\
0
\end{array}\right],
\end{aligned}
$$

where $\bar{u}=1-u$ is the inverse logic of $u$.

SM control is used to design a certain sliding surface in its control law. For this system, it is suitable to have a control law that adjusts a switching function $u$ as follows:

$$
\begin{aligned}
& u= \begin{cases}1 & \text { when } S>0, \\
0 & \text { when } S<0,\end{cases} \\
& u=\frac{1}{2(1+\operatorname{sign}(S))},
\end{aligned}
$$

where $S$ is the instantaneous state trajectory. We take the following surface:

$$
S=\alpha_{1} x_{1}+\alpha_{2} x_{2}+\alpha_{3} x_{3}=J^{T} x
$$

with $J^{T}=\left[\begin{array}{lll}\alpha_{1} & \alpha_{2} & \alpha_{3}\end{array}\right]$ and $\alpha_{1}, \alpha_{2}$, and $\alpha_{3}$ representing the control parameters, which are the sliding surface coefficients. The sliding surface can be obtained by enforcing $S=0$.

Finally, translation of the equivalent control function onto the duty ratio $d$, where

$$
0<d=\frac{V_{\mathrm{C}}}{V_{\text {ramp }}}<1
$$

gives the following relationship for the control signal $V_{C}$ and the ramp signal $V_{\text {ramp }}$ :

$$
\begin{gathered}
V_{C}=-\beta L\left[\left(\frac{\alpha_{1}}{\alpha_{2}}\right)-\left(\frac{1}{R_{1} C}\right)\right] i_{c} \\
+L C\left[\left(\frac{\alpha_{3}}{\alpha_{2}}\right)\left(V_{\text {ref }}-\beta V_{O}\right)\right] \\
+\beta\left(V_{O}-V_{i}\right) \\
V_{C}=-K_{p 1} i_{C}+K_{P 2}\left(V_{\text {ref }}-\beta V_{O}\right)+\beta\left(V_{O}-V_{i}\right) .
\end{gathered}
$$

Finally, the control parameters are chosen as

$$
\begin{aligned}
K_{p 1} & =\beta L\left(\frac{\alpha_{1}}{\alpha_{2}}-\frac{1}{R_{L} C}\right), \\
K_{p 2} & =L C\left(\frac{\alpha_{3}}{\alpha_{2}}\right), \\
V_{\text {ramp }} & =\beta\left(V_{O}-V_{i}\right), \\
\beta & =\frac{V_{\text {ref }}}{V_{d}} .
\end{aligned}
$$

Using the control voltage equation, the PWM-based SM controller for the boost converter can be implemented.
TABLE 2: Specifications of the DC-DC converter.

\begin{tabular}{lc}
\hline Designation & Values and components \\
\hline Capacitance $(C)$ & $300[\mu \mathrm{F}]$ \\
Inductance $(L)$ & $2[\mathrm{mH}]$ \\
Resistance $(R)$ & $150[\Omega]$ \\
Frequency $(f)$ & $10[\mathrm{kHz}]$ \\
\hline
\end{tabular}

\section{Results and Discussion}

Simulations of the MPPT system were carried out to verify the performance of the described approach. The system configuration is described in Section 4.1, while in Section 4.2, the tests used to compare the three algorithms using the series configuration under nonuniform insolation and constant temperature conditions are presented. In Section 4.3, we show that the tests verified the influence of temperature and insolation variations. The tests, which considered the response of all of the PV modules to nonuniform variations of temperature, insolation, and load changes, are presented in Section 4.4. Comparative simulation results are discussed in Section 4.5 .

4.1. Modeling of the Overall Photovoltaic Power System. The PV power system model implemented for this work comprised several parts. The overall model was made up of the following subsystem models:

(i) Matlab/SimPowerSystem model of a PV system,

(ii) SimPowerSystem model of a boost converter controlled with a PWM-based sliding mode controller.

The overall electrical circuit of the system, which was developed and implemented using Matlab/Simulink, is shown in Figure 8. The three PV generators were connected to a DC-DC boost converter, which could be controlled by a PWM-based sliding mode controller. The DC-DC boost converter specifications are reported in Table 2. Modeling of each stage is described in detail in Section 4.2.

4.2. Response of the Different MPPT Techniques to Nonuniform Insolation. In the implemented system, variations in insolation due to partially shaded conditions potentially caused by neighboring buildings, clouds, a tree in the wind, or towers, for example, were observed. All simulations were completed using the PV generator as defined above in the text, that is, a PV module with 54 cells connected in three series. For the period of this test, we also considered insolation increases or decreases. We performed a series of tests, and the responses of the proposed method to changes in insolation are presented.

We tested the behavior of the proposed method under partially shaded conditions with nonuniform insolation levels $G 1, G 2$, and $G 3$ varying from $400 \mathrm{~W} / \mathrm{m}^{2}$ to $950 \mathrm{~W} / \mathrm{m}^{2}$, as shown in Figures 9(a), 9(b), and 9(c). The temperature was kept constant at $T=25^{\circ} \mathrm{C}$. The dynamic response of the PV system was controlled by one of three algorithms, as shown in Figure 9(d). Based on the extracted characteristic curves, especially the power curves, power output under the 


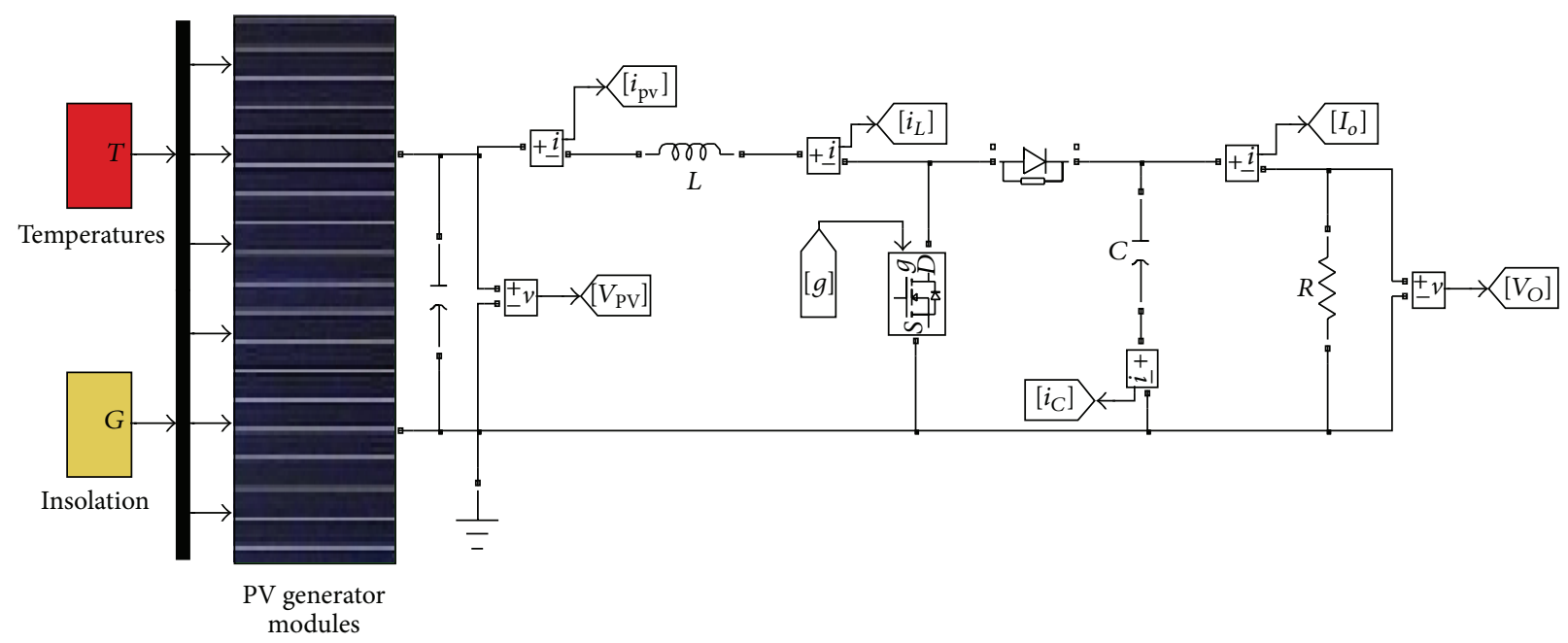

Figure 8: Matlab/SimPowerSystem block of the PV system.

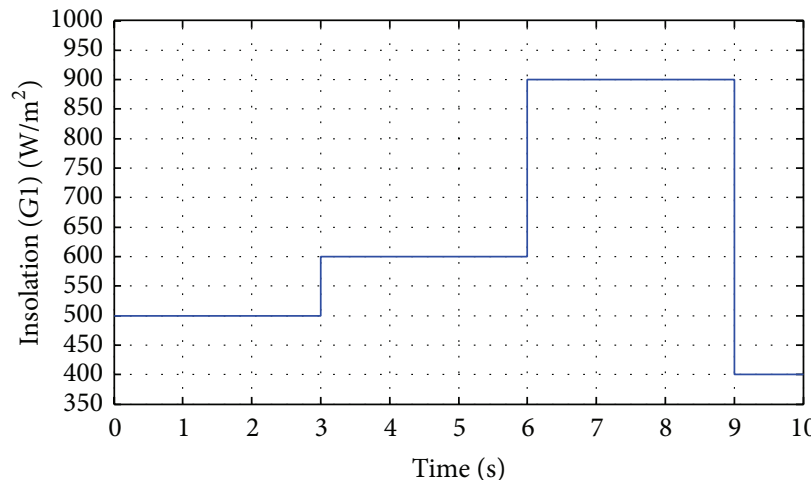

_ Insolation variation $(G 1)$

(a)

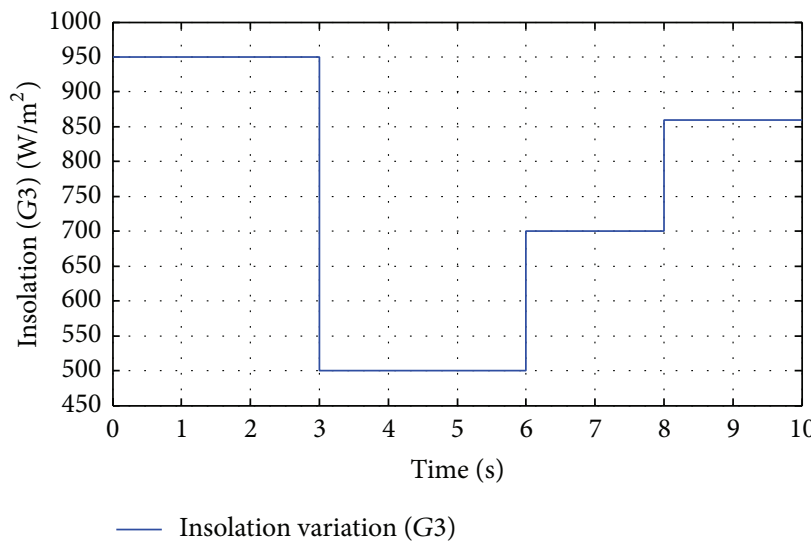

(c)

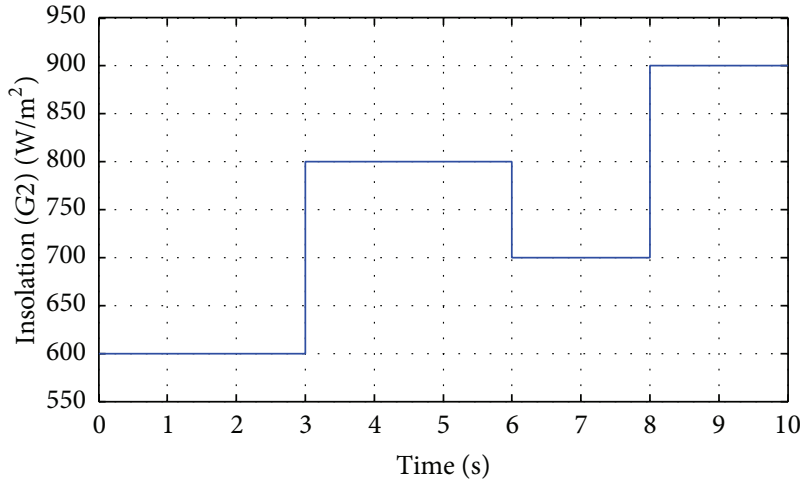

_ Insolation variation $(G 2)$

(b)

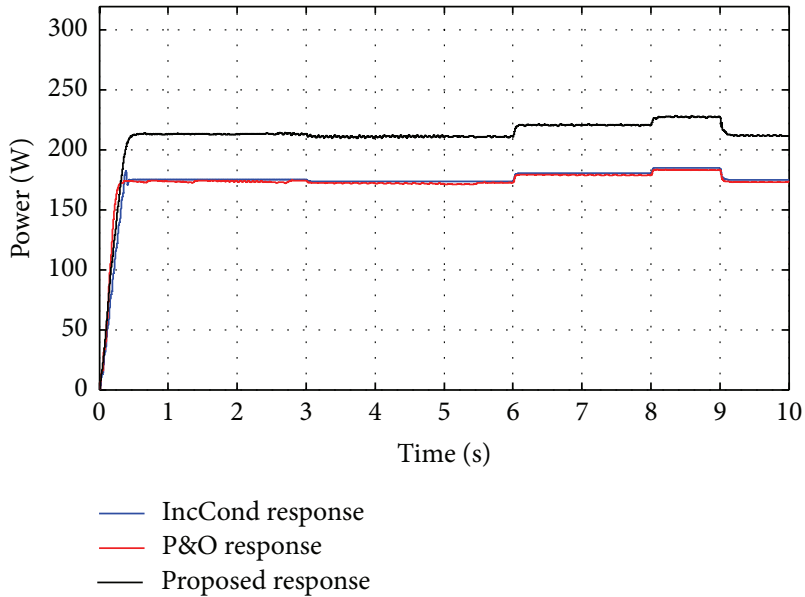

(d)

FIGURE 9: Influence of insolation variation on the three PV modules at a fixed temperature of $25^{\circ} \mathrm{C}$ : (a) insolation variation (G1); (b) insolation variation (G2); (c) insolation variation (G3); and (d) IncCond response (blue), P\&O response (red), and PWM based on the SVMC response (black) of PVG power. 


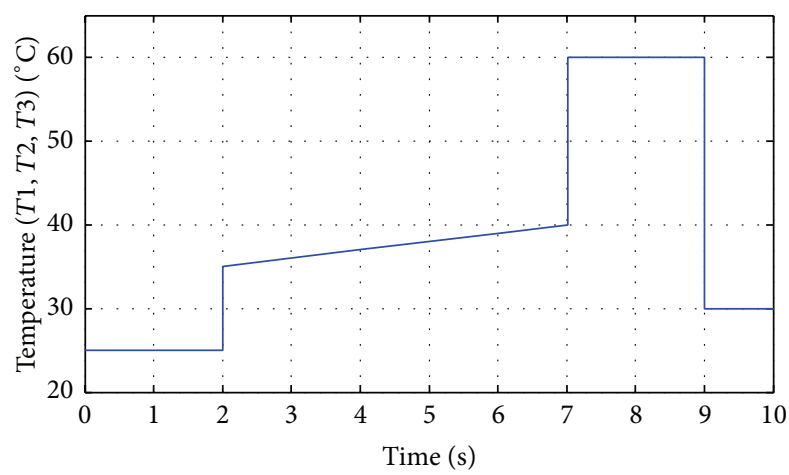

(a)

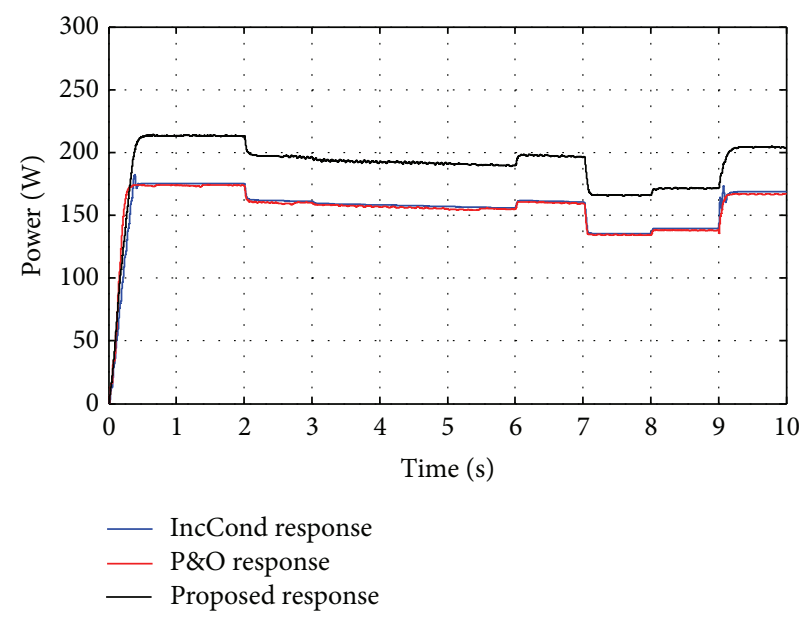

(b)

FIGURE 10: Influence of temperature variation of the three PV modules at constant insolation G: (a) temperature variations (T1, T2, T3) and (b) IncCond response (blue), P\&O response (red), and PWM based on SVMC response (black) of PVG power.

IncCond and $\mathrm{P} \& \mathrm{O}$ algorithms did not exceed $185.3 \mathrm{~W}$ and $183.5 \mathrm{~W}$, respectively. In contrast, a power output of $228.3 \mathrm{~W}$ was obtained under the PWM-based SVMC algorithm. The proposed algorithm stabilized around the GMPP with small oscillations. Therefore, the proposed algorithm resulted in $44.8 \mathrm{~W}$ more output power than the two conventional algorithms.

4.3. Response of the Different MPPT Techniques to Nonuniform Temperature. PV output power is affected by sudden temperature changes. Consequently, we investigated system performance in response to variations in temperature of the three PV modules. PV modules were exposed to constant insolation levels, $G 1=600 \mathrm{~W} / \mathrm{m}^{2}, G 2=800 \mathrm{~W} / \mathrm{m}^{2}$, and $G 3=1000 \mathrm{~W} / \mathrm{m}^{2}$, and then the temperature of the three PV modules was varied as shown in Figure 10(a). The dynamic response of the PV generator is shown in Figure 10(b). Responses using the IncCond and $\mathrm{P} \& \mathrm{O}$ algorithms did not exceed $175.4 \mathrm{~W}$ and $174.3 \mathrm{~W}$, respectively. In contrast, the proposed MPPT controller reached a high power of $213.9 \mathrm{~W}$. The proposed algorithm oscillated around the GMPP. The two conventional algorithms have $39.6 \mathrm{~W}$ less output power than the proposed algorithm.

\subsection{Response of the Different MPPT Techniques to Nonuniform} Atmospheric Conditions and Load Changes. We also investigated the dynamic behavior of the proposed system to rapid changes in load. To analyze the dynamic behavior of the system, we considered temperature, insolation, and step load changes. We performed tests in which the three PV modules were partially shaded with nonuniform insolation and temperature. Figure 11(a) shows the nonuniform temperature levels $T 1, T 2$, and $T 3$ varying from $20^{\circ} \mathrm{C}$ to $45^{\circ} \mathrm{C}$. Nonuniform insolation of the three PV modules was varied as shown in Figures 11(b), 11(c), and 11(d).

(i) Case 1 (test under rapidly changing load (from $150 \Omega$ to $220 \Omega$ )). Step load change was from $150 \Omega$ to $220 \Omega$ at time $t=5 \mathrm{sec}$. The dynamic responses of the PV system controlled by the three algorithms are represented in Figure 11(e). The proposed algorithm oscillated around the GMPP and the PWM-based sliding mode algorithm showed much better performance and was more robust than the $\mathrm{P} \& \mathrm{O}$ and IncCond algorithms.

(ii) Case 2 (test under rapidly changing load (from 150 to $550 \Omega)$ ). The step load change was from $150 \Omega$ to $550 \Omega$ at time $t=5 \mathrm{sec}$. With reference to Figure 11(f), the simulation results showed that proposed method has better performance than the existing methods. However, when the overload level changed rapidly at $5 \mathrm{sec}$, the proposed method has a slow stability output power response time.

4.5. Comparative Study. Flowcharts of the $\mathrm{P} \& \mathrm{O}$ and IncCond methods developed using Matlab/Simulink software are shown in Figures 5 and 6, respectively.

Previously developed methods $[5,7,18]$ for a resistive load connected to a DC-DC converter were simulated. However, we considered static and dynamic loads and the influence of nonuniform insolation and temperature on all PV modules to evaluate their performance. Figures 9(d), 10(b), and 11(e) show the output power of the three methods under partially shaded conditions. All methods were able to track the GMPP with different output voltages. Specifically, the IncCond method was characterized by a small overshoot and oscillation when the MPP was reached, whereas the P\&O method has more oscillation around the GMPP. Finally, the proposed method has more oscillation around the GMPP than the P\&O method; however, it provided more output power than expected, and its implementation was relatively conventional. In addition, an abrupt change in output load resulted in slower stability output power. The proposed method showed more robustness in terms of its dynamic behavior under different operating conditions, such as nonuniform insolation, nonuniform temperature, and resistive load, than the conventional methods evaluated. 


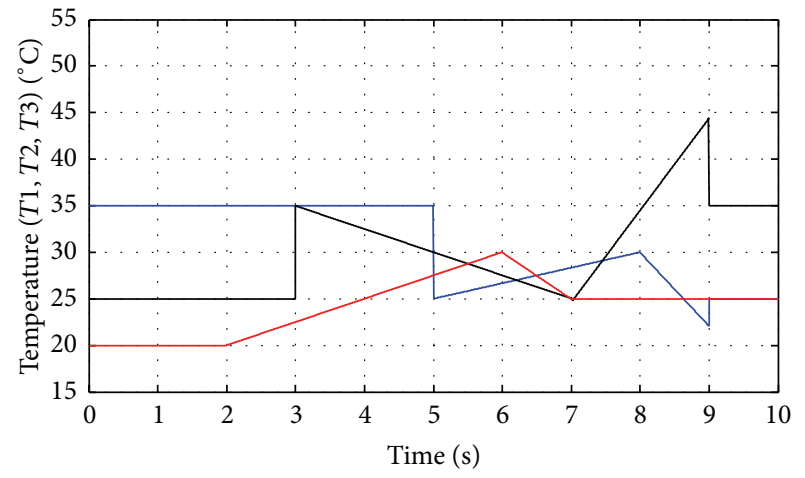

- Temperature (T1)

— Temperature (T2)

_ Temperature (T3)

(a)

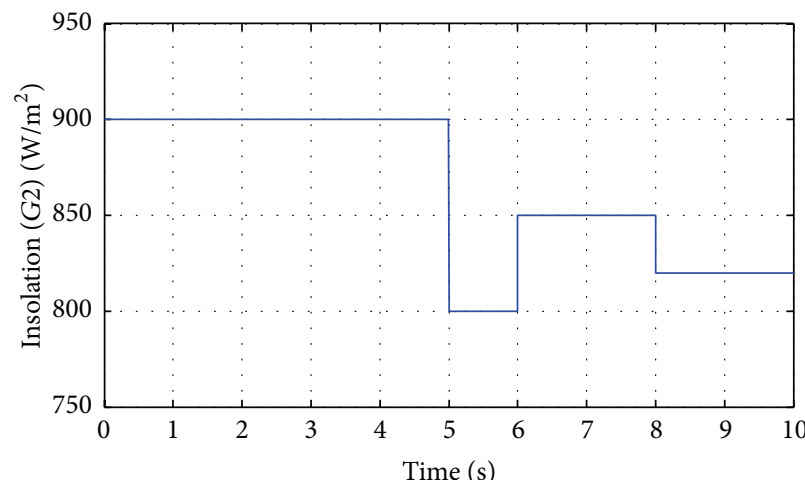

_ Insolation variation (G2)

(c)

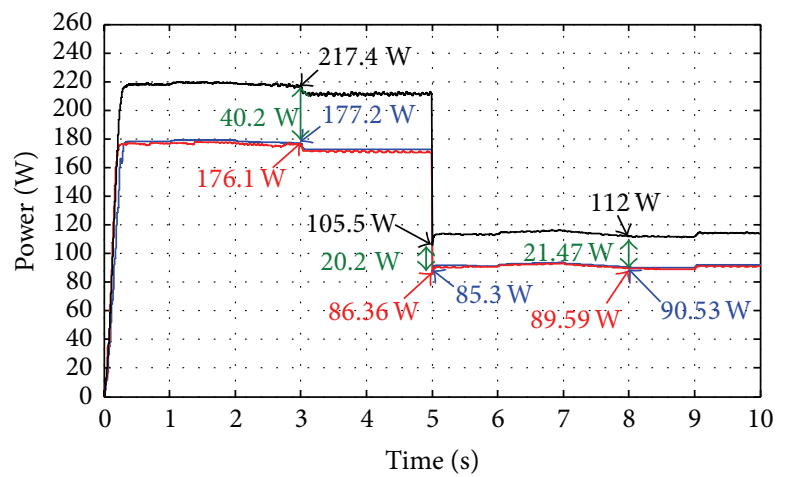

- IncCond response

— P\&O response

- Proposed response

(e)

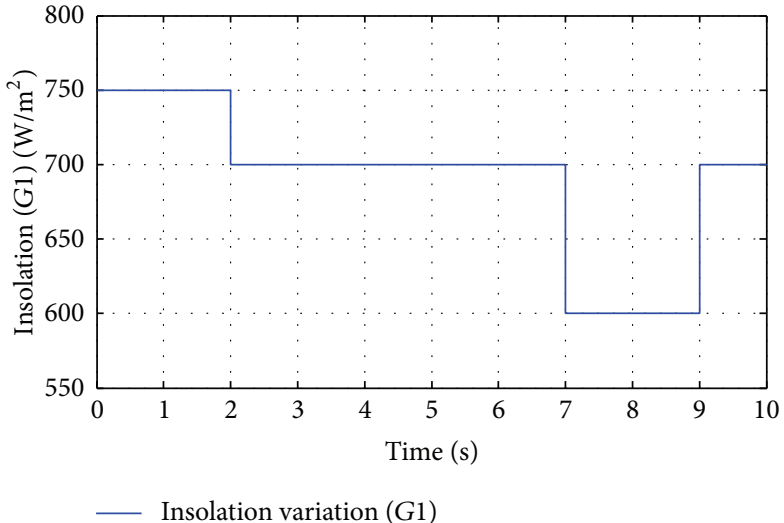

(b)

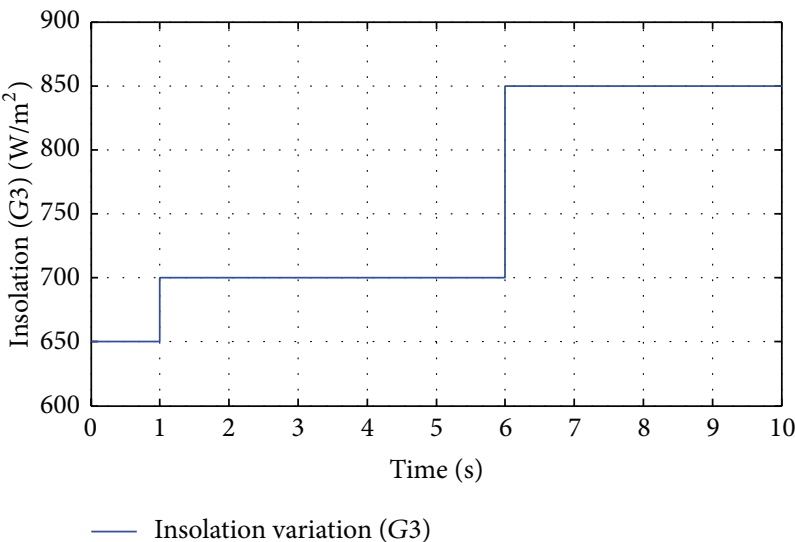

(d)

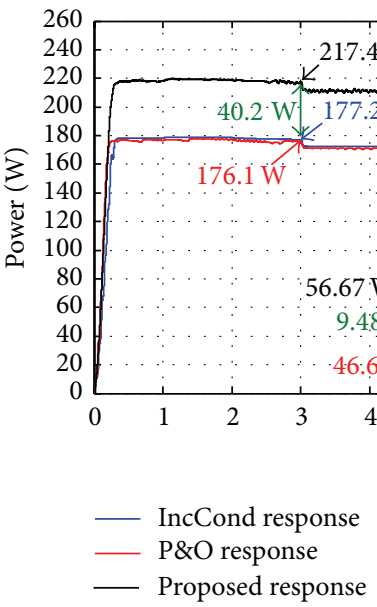

(f)

FIGURE 11: Influence of temperature and insolation variations of the three PV modules: (a) temperature variations (T1, T2, and T3); (b) insolation variation $(G 1)$; (c) insolation variation (G2); (d) insolation variation (G3); (e) IncCond response (blue), P\&O response (red), and PWM based on SVMC response (black) of the PVG power to a step load change from 150 to $220 \Omega$; and (f) IncCond response (blue), P\&O response (red), and PWM based on SVMC response (black) of the PVG power to a step load change from 150 to $550 \Omega$. 
TABLE 3: The result of power improvement ratio.

\begin{tabular}{lcc}
\hline & $\begin{array}{c}\text { IncCond and } \\
\text { proposed method } \\
\text { power ratio (\%) }\end{array}$ & $\begin{array}{c}\text { P\&O and proposed } \\
\text { method } \\
\text { power ratio (\%) }\end{array}$ \\
\hline Section 4.2 & 21.775 & 22.694 \\
Section 4.3 & 21.709 & 22.633 \\
Section 4.4 (Case 1) & 22.965 & 23.660 \\
Section 4.4 (Case 2) & 24.892 & 25.497 \\
\hline
\end{tabular}

\section{Conclusions}

Generation of power from a PV system is highly dependent on climate conditions. In this paper, we assessed the performance of three different MPPT techniques in response to uniform and nonuniform insolation, temperatures, and loads. In particular, we compared the performance of the $\mathrm{P} \& \mathrm{O}$ and IncCond MPPT techniques with our proposed MPPT technique. The ability of the proposed method supplied with the reference voltage by the MPPT at sampling time to respond to sudden changes in solar insolation, temperature, and load was tested. The proposed method converged quickly with small oscillations around the MPP during steady state and obtained a higher voltage than the other two methods. Matlab/SimPowerSystem-based simulations of a PV system with MPPT control were carried out to validate the proposed method.

Table 3 is shown as the result of the improved power ratio based on our proposed scheme.

\section{Future Work}

Our results demonstrate that the proposed method successfully tracked output power consumption. However, the proposed method has slow response time to a rapid change in load. Therefore, more studies are necessary to improve the response time to a sudden demand load.

\section{Conflict of Interests}

The authors declare that there is no conflict of interests regarding the publication of this paper.

\section{References}

[1] E. C. Kern Jr., E. M. Gulachenski, and G. A. Kern, "Cloud effects on distributed photovoltaic generation: slow transients at the Gardner, Massachusetts photovoltaic experiment," IEEE Transactions on Energy Conversion, vol. 4, no. 2, pp. 184-190, 1989.

[2] M. Calais and H. Hinz, "A ripple-based maximum power point tracking algorithm for a single-phase, grid-connected photovoltaic system," Solar Energy, vol. 63, no. 5, pp. 277-282, 1998.

[3] D. Sera, T. Kerekes, R. Teodorescu, and F. Blaabjerg, "Improved MPPT method for rapidly changing environmental conditions," in Proceedings of the IEEE International Symposium on Industrial Electronics (ISIE '06), pp. 1420-1425, July 2006.

[4] C. W. Tan, T. C. Green, and C. A. Hernandez-Aramburo, "An improved maximum power point tracking algorithm with current-mode control for photovoltaic applications," in Proceedings of the International Conference on Power Electronics and Drives Systems (PEDS '05), pp. 489-494, 2005.

[5] T. Esram and P. L. Chapman, "Comparison of photovoltaic array maximum power point tracking techniques," IEEE Transactions on Energy Conversion, vol. 22, no. 2, pp. 439-449, 2007.

[6] E. Koutroulis, K. Kalaitzakis, and N. C. Voulgaris, "Development of a microcontroller-based, photovoltaic maximum power point tracking control system," IEEE Transactions on Power Electronics, vol. 16, no. 1, pp. 46-54, 2001.

[7] A. Zegaoui, M. Aillerie, P. Petit, J. P. Sawicki, J. P. Charles, and A. W. Belarbi, "Dynamic behaviour of PV generator trackers under irradiation and temperature changes," Solar Energy, vol. 85, no. 11, pp. 2953-2964, 2011.

[8] B. N. Alajmi, K. H. Ahmed, S. J. Finney, and B. W. Williams, "A maximum power point tracking technique for partially shaded photovoltaic systems in microgrids," IEEE Transactions on Industrial Electronics, vol. 60, no. 4, pp. 1596-1606, 2013.

[9] A. Reza Reisi, M. Hassan Moradi, and S. Jamasb, "Classification and comparison of maximum power point tracking techniques for photovoltaic system: a review," Renewable and Sustainable Energy Reviews, vol. 19, pp. 433-443, 2013.

[10] S.-C. Tan, Y. M. Lai, and C. K. Tse, "Implementation of pulsewidth-modulation based sliding mode controller for boost converters," IEEE Power Electronics Letters, vol. 3, no. 4, pp. 130135, 2005.

[11] S.-C. Tan, Y. M. Lai, C. K. Tse, and L. Martinez-Salamero, "Special family of PWM-based sliding-mode voltage controllers for basic DC-DC converters in discontinuous conduction mode," IET Electric Power Applications, vol. 1, no. 1, pp. 64-74, 2007.

[12] G. Spiazzi, P. Mattavelli, L. Rossetto, and L. Malesani, "Application of sliding mode control to switch-mode power supplies," Journal of Circuits, Systems, and Computers, vol. 5, pp. 337-354, 1995.

[13] B. Subudhi and R. Pradhan, "A comparative study on maximum power point tracking techniques for photovoltaic power systems," IEEE Transactions on Sustainable Energy, vol. 4, no. 1, pp. 89-98, 2013.

[14] Y. T. Tan, D. S. Kirschen, and N. Jenkins, "A model of PV generation suitable for stability analysis," IEEE Transactions on Energy Conversion, vol. 19, no. 4, pp. 748-755, 2004.

[15] V. Salas, E. Olías, A. Barrado, and A. Lázaro, "Review of the maximum power point tracking algorithms for stand-alone photovoltaic systems," Solar Energy Materials and Solar Cells, vol. 90, no. 11, pp. 1555-1578, 2006.

[16] K. Ishaque and Z. Salam, "A review of maximum power point tracking techniques of PV system for uniform insolation and partial shading condition," Renewable and Sustainable Energy Reviews, vol. 19, pp. 475-488, 2013.

[17] C. Hua, J. Lin, and C. Shen, "Implementation of a DSP-controlled photovoltaic system with peak power tracking," IEEE Transactions on Industrial Electronics, vol. 45, no. 1, pp. 99-107, 1998.

[18] A. Safari and S. Mekhilef, "Simulation and hardware implementation of incremental conductance MPPT with direct control method using cuk converter," IEEE Transactions on Industrial Electronics, vol. 58, no. 4, pp. 1154-1161, 2011. 

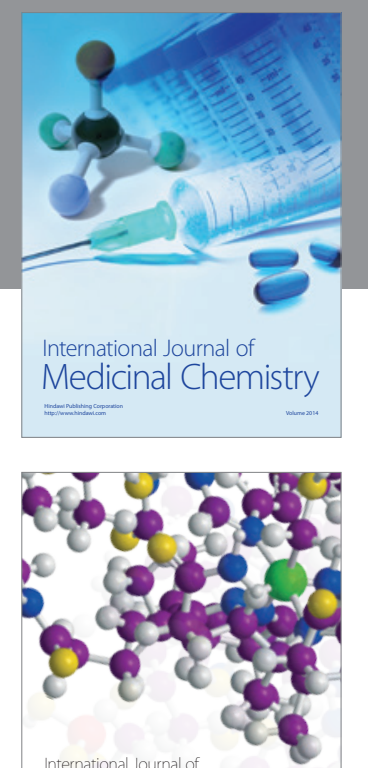

\section{Carbohydrate} Chemistry

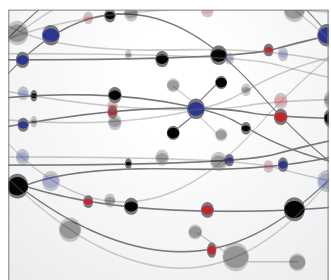

The Scientific World Journal
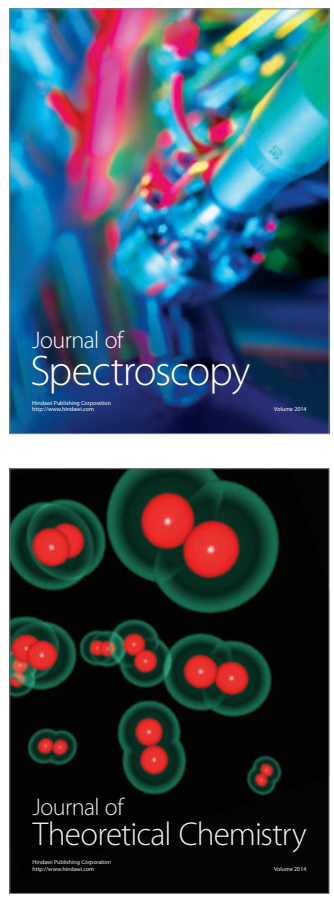
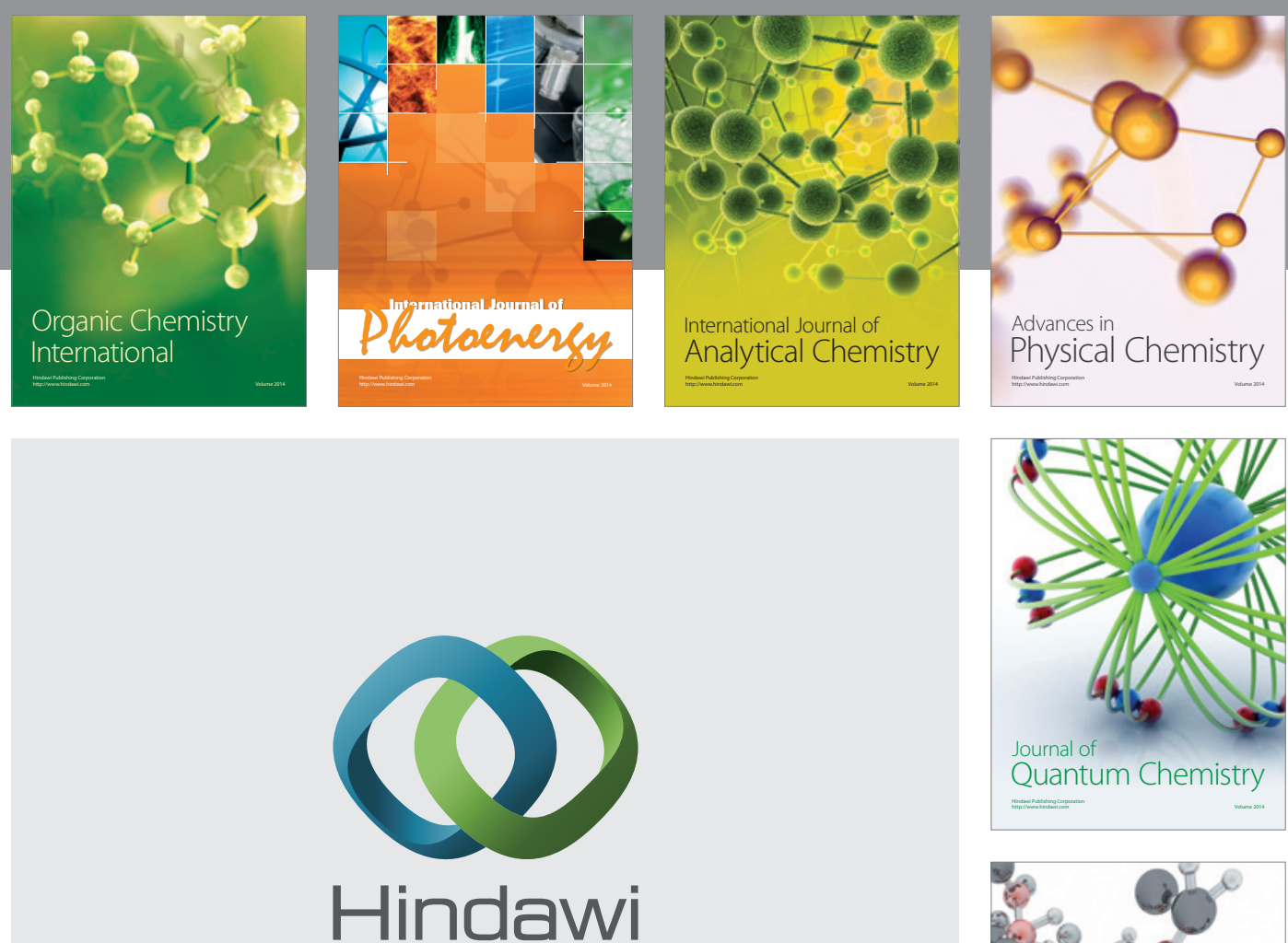

Submit your manuscripts at

http://www.hindawi.com

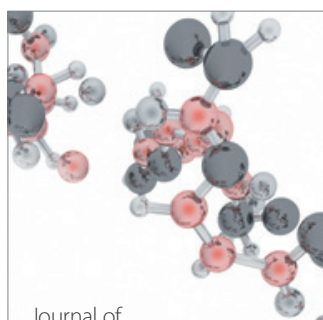

Analytical Methods

in Chemistry

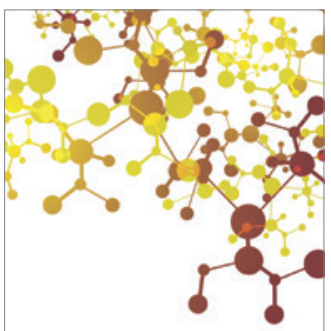

Journal of

Applied Chemistry

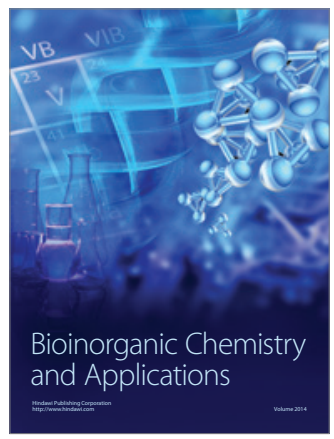

Inorganic Chemistry
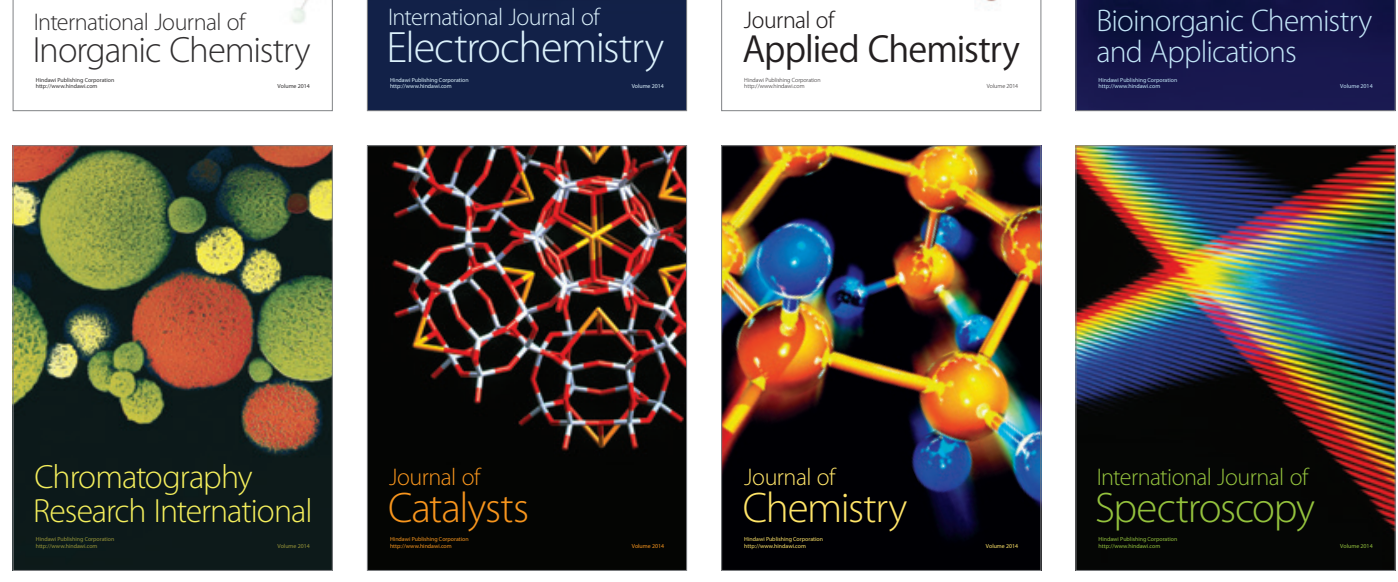